\title{
The Prevalence and Correlates of Eating Disorders among Emergency Department Patients Aged 14-20 Years
}

\author{
Suzanne Dooley-Hash, MD ${ }^{1,2 *}$ \\ Judith D. Banker, MA, LLP, FAED ${ }^{2}$ \\ Maureen A. Walton, MPH, $\mathrm{PhD}^{3}$ \\ Yarden Ginsburg, MS $^{3}$ \\ Rebecca M. Cunningham, MD ${ }^{1,4}$
}

\begin{abstract}
Objective: This study describes the rates of eating disorders in patients who present to the emergency department (ED) for any reason and examines the relationship between eating disorders, depression, and substance use in these patients.
\end{abstract}

Method: ED patients aged 14-20 years $(n=942)$ completed a computerized questionnaire. Analyses were conducted comparing individuals who screened positive for an eating disorder with those who did not based on demographics (gender, age, race, and public assistance), body mass index, substance use, and depression.

Results: Sixteen percent of patients screened positive for an eating disorder.
These patients were more likely to also screen positive for depression and substance use. Males accounted for $26.6 \%$ of all eating disorders, and no difference was seen in rates across ethnic or income groups.

Discussion: Eating disorders are common amongst all patients aged 14-20 years presenting to the ED and are associated with high rates of psychiatric comorbidity. (C) 2012 by Wiley Periodicals, Inc.

Keywords: prevalence; screening; emergency department; eating disorders

(Int J Eat Disord 2012; 45:883-890)

\section{Introduction}

Although frequently thought to have a relatively low prevalence in the general population, eating disorders are actually among the most prevalent psychiatric problems in adolescents and young adults and are one of the top three most common chronic conditions in these age groups. ${ }^{1}$ In fact, some experts estimate that as many as $14 \%$ of adolescents have some form of clinically significant eating disorder, ${ }^{1,2}$ and rates as high as $7-21 \%$ have been found in screening studies in both the general population and primary care settings. ${ }^{3-5}$ Patients with eating disorders have also been found to have overall increased utilization of all healthcare services including emergency departments (EDs) ${ }^{6,7}$ At

\footnotetext{
Accepted 11 April 2012

Supported by Contract grant sponsor: National Institute on Alcohol Abuse and Alcoholism (NIAAA); contract grant number: AA018122

*Correspondence to: Suzanne Dooley-Hash, MD, Department of Emergency Medicine, University of Michigan, Ann Arbor, MI. E-mail:sldh@umich.edu

${ }^{1}$ Department of Emergency Medicine, University of Michigan, Ann Arbor, Michigan

${ }^{2}$ The Center for Eating Disorders, Ann Arbor, Michigan

${ }^{3}$ Department of Psychiatry, University of Michigan, Ann Arbor, Michigan

${ }^{4}$ Department of Emergency Medicine, University of Michigan Injury Center, Ann Arbor, Michigan

Published online 8 May 2012 in Wiley Online Library (wileyonlinelibrary.com). DOI: 10.1002/eat.22026

(C) 2012 Wiley Periodicals, Inc.
}

least one study has shown that the average number of $\mathrm{ED}$ visits was increased in patients with eating disorders who eventually died from their illness when compared with controls, which raises concerns that the patients with eating disorder who do present to the ED for care may have an increased severity of disease. ${ }^{8}$

Mood disorder and substance use disorder (SUD) and other health risk behaviors are common in this age group as well. There is also strong evidence demonstrating high rates of comorbidity of eating disorders with both mood disorder ${ }^{9}$ and SUD. ${ }^{10-13}$ Some findings indicate that substance use may even be mediated by binge eating status in some patients. ${ }^{14,15}$ The prevalence of SUD in individuals with eating disorders is $\sim 50 \%$ compared with an $\sim 9 \%$ prevalence in the general population. ${ }^{16}$ Likewise, more than $35 \%$ of individuals with SUD report also having an eating disorder compared with $1-3 \%$ in the general population. ${ }^{16,17}$

In addition to high rates of comorbidity, eating disorders, along with SUD, have the highest rate of mortality of any mental illness, including major depression and schizophrenia. ${ }^{8,18-21}$ Much of the excess mortality in eating disorders is related to suicide, ${ }^{21,22}$ and studies have found that almost one-third of patients with an eating disorder will attempt suicide ${ }^{23}$ at some point during their illness. Predictors of suicide attempts as well as mortality from suicide or any cause in patients with eating 
disorder include depression and drug or alcohol use. $^{23,24}$

The ED is an important source of healthcare for many young people and may be the only access to care for some, especially the uninsured or underinsured. ${ }^{25}$ Increased utilization of healthcare resources including the ED has also been seen in all psychiatric conditions including eating disorders, mood disorder, and SUD. ${ }^{6,7}$ Given the large numbers of patients who present to EDs annually and the lack of access to other healthcare care for many, better understanding of these conditions and their relationships in the ED setting is important as it may facilitate the identification and treatment of all three.

The objectives of the current study were to: (1) determine the prevalence and characteristics of patients with eating disorders who present to the ED for any reason and (2) assess the relationship between eating disorders and mood disorder and SUD in these patients.

\section{Method}

\section{Study Design and Setting}

Study participants were recruited to complete a screening survey in the ED of a level 1 trauma center, the University of Michigan Medical Center in Ann Arbor, Michigan, as part of a larger study, Project UConnect. Approval of study procedures was obtained from the University of Michigan's institutional review board before start of the study. A Certificate of Confidentiality for human participants was obtained through the National Institutes of Health.

Patients aged 14-20 years presenting to the ED for medical care from October 15, 2010 to March 1, 2011 were eligible for screening. Patients seeking care for suicidal ideation, sexual assault, child abuse, altered mental status, or neurological impairment precluding consent or who were non-English speaking, combative, in police custody, visually or hearing impaired, or aged 17 and under with no parent/guardian available for consent were excluded from participation. Patients that were too ill to be screened in the ED were eligible for approach during their inpatient visit.

Potential study participants were identified through an electronic patient tracking log and recruited by research assistants (RAs) in patient treatment areas. After written consent was obtained, participants were instructed on the use of a touchscreen tablet computer, which they used to independently complete a 20 -min screening survey. Each participant received a $\$ 1.00$ gift following completion of the survey.

\section{Study Measures}

Demographics. Demographic information collected included gender, age, race, Hispanic ethnicity (no/yes), and receipt of public assistance (yes/no). Receipt of public aid was defined as participants who reported that they, their parents, or "the most important person raising you" received some form of public assistance (described as welfare, Bridge Card, EBT, disability benefits).

Body Mass Index. Body mass index (BMI) was calculated from self-reported height and weight [BMI = weight in pounds/(height in inches) ${ }^{2} \times 703$ ]. Patients were then categorized based on BMI as underweight (BMI: <18.5), normal (BMI: 18.5-24.9), overweight (BMI: 25.0-29.9), and obese (BMI: $\geq 30.0$ ) as defined by the World Health Organization. ${ }^{26}$ For purposes of statistical analysis, underweight was categorized with normal weight because of the small number of underweight participants.

Eating Disorders. A modified version of a previously validated, self-report questionnaire, the SCOFF, was used to screen for the presence of eating disorders. ${ }^{5,27-29}$ The SCOFF consists of five yes/no questions that address the core features of anorexia nervosa (AN) and bulimia nervosa (BN). Two or more "yes" answers constitute a positive SCOFF and indicate a likely eating disorder case. Use of the original SCOFF with a cutoff score of $\geq 2$ positive answers has been validated in multiple prior studies and found to be both sensitive (72-100\%) and specific (73$94 \%$ ) for the diagnosis of AN and BN. ${ }^{5,27-29}$ For this study, minor modifications were made to the original SCOFF questionnaire to reflect the younger age of our patient population, linguistic differences between the United States and the United Kingdom (i.e., "stone" changed to "pounds"), and to broaden the questionnaire's diagnostic scope to include binge eating disorder (BED) and other forms of eating disorders not otherwise specified (EDNOS) (Fig. 1). For the purposes of analyses, a cutoff score of $\geq 2$ positive answers on the mSCOFF was considered positive for an eating disorder.

Depression. The abbreviated Patient Health Questionnaire (PHQ-2) was used to measure depressive symptoms. The PHQ-2 consists of the first two questions of the original nine-item PHQ, which assess the core features of depression: depressed mood and anhedonia. ${ }^{30} \mathrm{~A}$ cutoff score of $\geq 3$ on the PHQ-2, which has previously been shown to be effective in screening for major depression, was used for analyses. ${ }^{31,32}$

Alcohol Use. The Alcohol Use Disorders Identification Test (AUDIT)-C, which consists of the first three questions (consumption items) of the 10-item AUDIT, was used to assess for risky drinking behavior during the past 3 months. Cutoff scores of 3 for adolescents 14-17 years old ${ }^{33}$ and 4 for those $18-20^{34}$ have previously been shown to be both sensitive and specific for identifying alcohol 
FIGURE 1. Comparison of original SCOFF and modified SCOFF questionnaires.

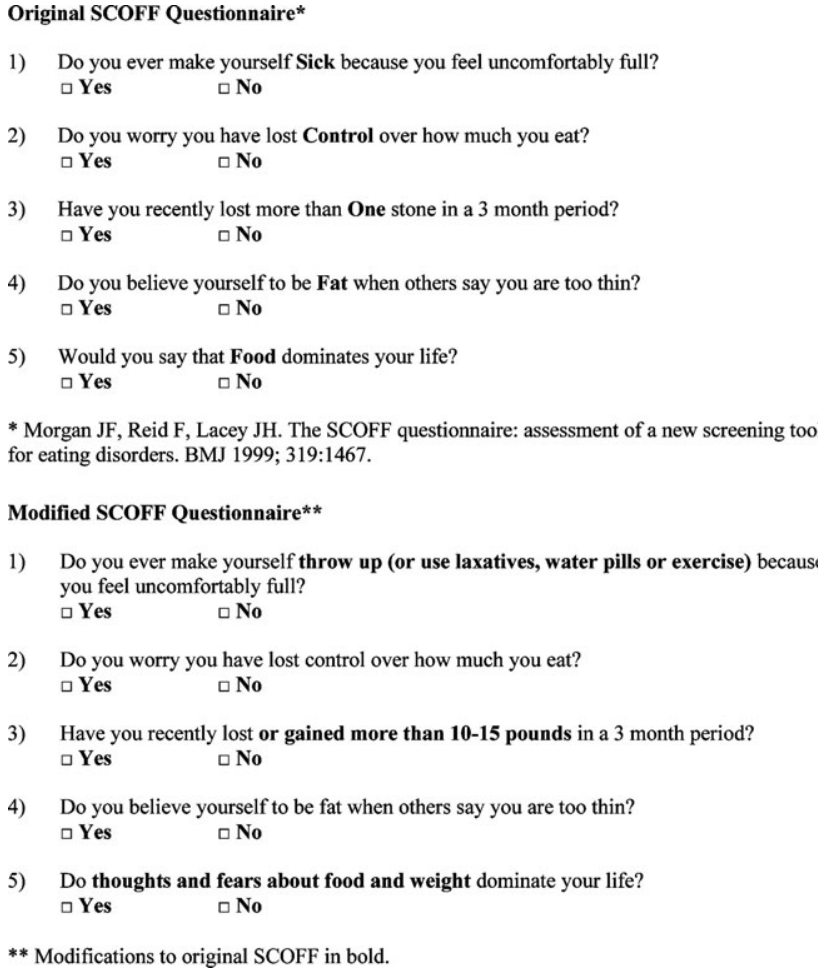

use disorders and risky drinking in these age groups. This measure has been shown to be a good predictor of future alcohol-related social and medical problems. ${ }^{35,36}$ For the purposes of analyses in this study, an AUDIT-C score $\geq 3$ for participants aged 14-17 years or $\geq 4$ for those 18-20 was considered positive for the presence of risky drinking behavior.

Substance Use. Questions were also taken from the Alcohol, Smoking and Substance Involvement Screening Test to screen for any use of tobacco and/or drugs including tobacco, over-the-counter, illicit, and nonmedical prescription drug use over the past 3 months. ${ }^{37}$ For the purposes of analyses, variables were dichotomously coded (no use/any use) in these groups: tobacco, cannabis, stimulants (includes methamphetamine, cocaine, and prescription stimulants), and other drugs (inhalants, hallucinogens, illicit and prescription opioids, dextromethorphan, and sedatives).

\section{Statistical Analysis}

Patients who screened positive for an eating disorder were compared with those who screened negative in a bivariate analysis. Statistical significance of these comparisons was determined with the $\chi^{2}$ test (for categorical variables) or $t$-test (age), where significance was defined as $p<.05$. Logistic regression was used to identify variables independently associated with self-reported eating disorder behavior. Unadjusted and adjusted odds ratios
(ORs) and 95\% confidence intervals (CIs) are reported. The Hosmer-Lemeshow test was used to assess the fit of the final model. ${ }^{38}$ Data were analyzed in SAS Version 9.2 (SAS Institute, Cary, NC).

\section{Results}

A total of 1,379 patients were eligible for screening during this study. Of these, 1,142 (82.8\%) were approached for screening, whereas 237 (17.2\%) were missed by RAs. Of the patients approached, 200 (17.5\%) refused to participate and 942 (82.5\%) participated (Fig. 2). Fifty of these (5.3\%) did not complete all five of the SCOFF questions. Baseline characteristics between these patients and those who completed all five questions were not significantly different and they were excluded from the final analyses (data not shown). The average age of the patients sampled was 17.7 years (SD 1.9). The majority of patients were Caucasian $(78.6 \%)$ and females were slightly more prevalent than males (54.9 vs. $45.1 \%$ ). Receipt of public assistance was seen in $28.2 \%$. As indicated by a positive mSCOFF $(\geq 2$ positive answers), $16.0 \%$ of patients in this sample screened positive for an eating disorder. According to BMI calculated from self-reported height and weight, $69.2 \%$ of patients were normal or underweight (BMI: $\leq 25$ ), whereas $19.3 \%$ were overweight (BMI: 25-30) and $11.5 \%$ were obese (BMI: $>30$ ) (Table 1 ).

Bivariate analysis of baseline characteristics in patients who screened positive for an eating disorder demonstrated that they were 2.6 times more likely to be female (OR: 2.6, 95\% CI: 1.7-3.9, $p<$ $.001)$. Average BMI was higher in the patients with eating disorders $(26.0 \pm 6.3$ vs. $23.2 \pm 4.6, p<.001)$ and they were 3.4 times more likely to be obese (95\% CI: $2.1-5.4, p<.001$ ) or on public assistance (OR: $1.8,95 \%$ CI: $1.3-2.7, p=.001$ ) than the patients with noneating disorder. There were no significant differences between groups for age or race (Table 2).

Also, by bivariate analysis, depression and/or substance use were associated with the presence of an eating disorder. Depression was significantly higher in patients who screened positive for an eating disorder (OR: 4.3, 95\% CI: 2.8-6.6, $p<.001$ ) as was the presence of risky drinking (OR: 1.9, 95\% CI: $1.3-2.8, p<.001$ ) and tobacco (OR: 2.3, 95\% CI: $1.6-3.4, p<.001$ ), cannabis (OR: 1.7 , 95\% CI: $1.2-$ $2.5, p=.002$ ), stimulants (OR: 3.9, 95\% CI: 2.4-6.4, $p<.001$ ), and other drug use (OR: 2.4 , 95\% CI: $1.7-$ 3.6, $p<.001$ ) (Table 2).

In logistic regression analyses, gender, BMI, depression, risky drinking, and stimulant use were 
FIGURE 2. UConnect flow chart. Patients aged 14-20 years presenting to the ED from October 15, 2010 to March 1, 2011.

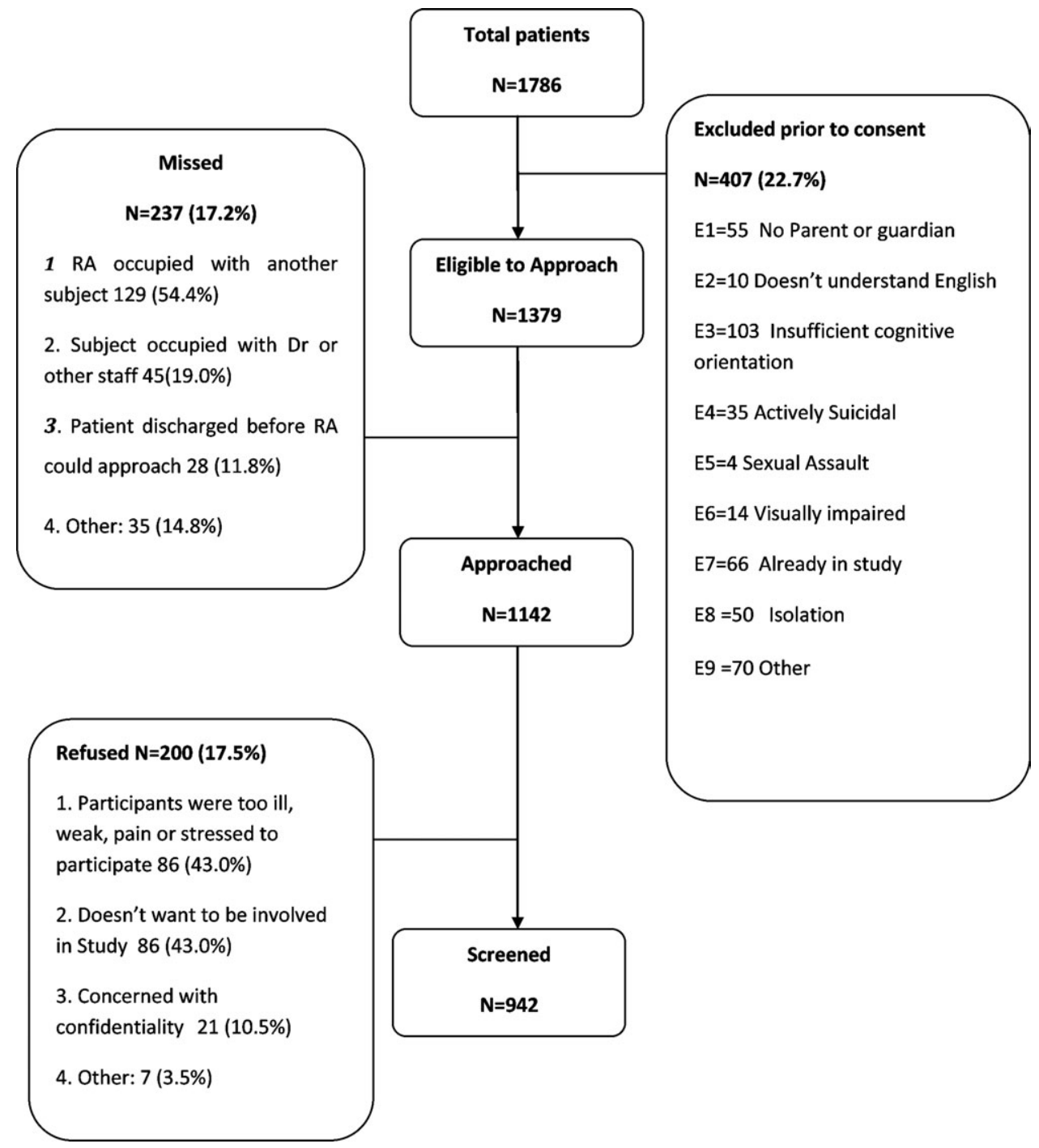

TABLE 1. Demographics and prevalence of eating disorders among ED patients aged 14-20 $(n=892)$

\begin{tabular}{lcc}
\hline & $N$ & $\%$ \\
\hline Age-mean (SD) & $17.7(1.9)$ & - \\
Female & 490 & 54.9 \\
Caucasian & 685 & 78.6 \\
BMI & 617 & \\
$\quad<25$ (low or normal) & 172 & 69.2 \\
$25-30$ (overweight) & 103 & 11.5 \\
$\quad>30$ (obese) & 143 & 16.0 \\
Eating disorder (SCOFF $\geq 2)$ & & \\
\hline
\end{tabular}

significantly related to having an eating disorder (Table 3). Patients with eating disorder were more likely to be female (adjusted OR: 3.27, 95\% CI: 2.085.14, $p<.001$ ), obese (adjusted OR: 3.40, 95\% CI: 1.98-5.83, $p<.001$ ), and/or depressed (adjusted OR: 3.31, 95\% CI: 2.02-5.41, $p<.001$ ) than patients with noneating disorder. They were also more likely to exhibit risky drinking behavior (adjusted OR: 1.91, 95\% CI: $1.14-3.19, p=.01$ ) or use stimulants (adjusted OR: 2.08, 95\% CI: 1.11-3.90, $p=.02)$. The associations between eating disorders and public assistance, the use of any amount of alcohol, and/or the use of all other substances were not significant in the multivariate analysis (public aid $p=.47$, tobacco use $p=.13$, cannabis use $p=.17$, and other drug use $p=.11)$.

\section{Discussion}

This study had several important findings. First, the observed prevalence of eating disorders, $16.0 \%$, 
TABLE 2. Comparison of baseline characteristics between patients who screen positive vs. negative for eating disorders

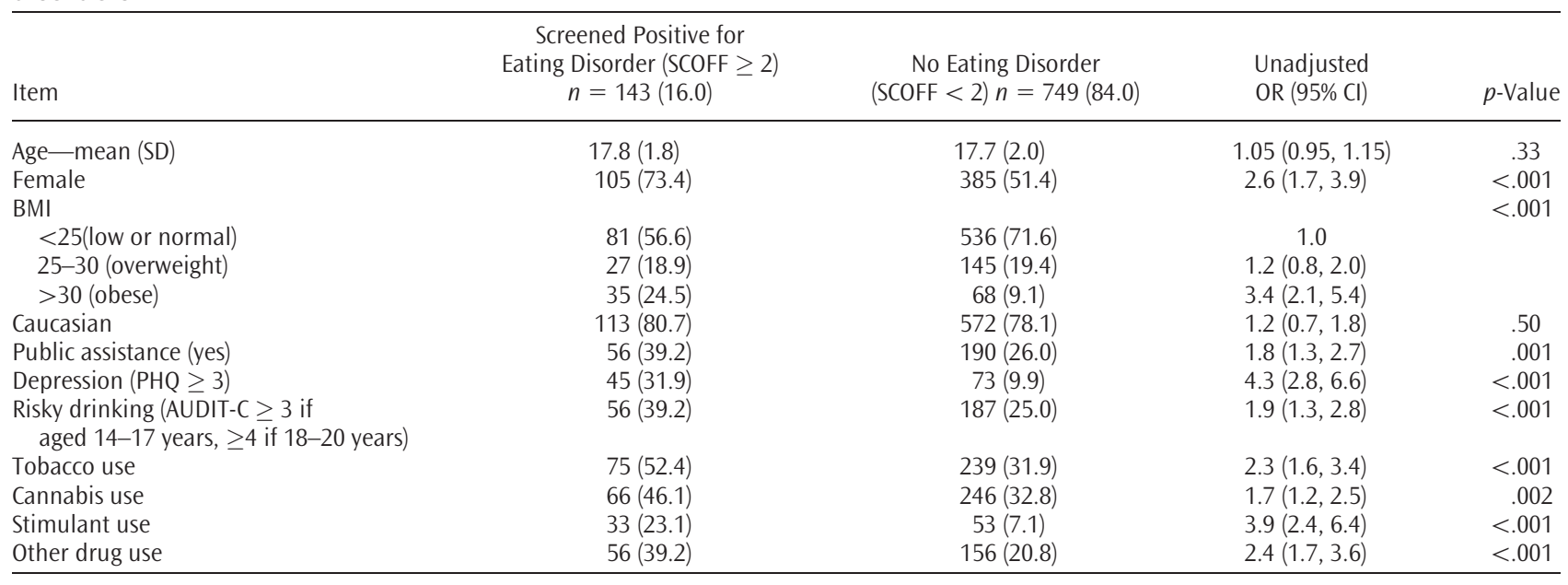

TABLE 3. Logistic regression evaluating the association of demographics, BMI and substance use to a positive screen for an eating disorder $(n=892)^{a}$

\begin{tabular}{|c|c|c|c|}
\hline & $\begin{array}{l}\text { Screened Positive for } \\
\text { Eating Disorder } \\
\text { (SCOFF } \geq 2) \\
\text { Adjusted OR }\end{array}$ & $95 \% \mathrm{Cl}$ & $p$-Value \\
\hline Female & 3.27 & $(2.08,5.14)$ & $<.001$ \\
\hline BMI & & & $<.001$ \\
\hline <25 (low or normal) & 1.0 & & \\
\hline 25-30 (overweight) & 1.31 & $(0.77,2.21)$ & \\
\hline$>30$ (obese) & 3.40 & $(1.98,5.83)$ & \\
\hline On public aid & 1.18 & $(0.75,1.85)$ & .47 \\
\hline Depression (PHQ $\geq 3$ ) & 3.31 & $(2.02,5.41)$ & $<.001$ \\
\hline $\begin{array}{l}\text { Risky drinking (AUDIT-C } \geq 3 \\
\text { if aged } \\
14-17 \text { years, } \geq 4 \\
\text { if } 18-20 \text { years) }\end{array}$ & 1.91 & $(1.14,3.19)$ & .01 \\
\hline Tobacco use & 1.48 & $(0.89,2.46)$ & 13 \\
\hline Cannabis use & 0.69 & $(0.40,1.18)$ & 17 \\
\hline Stimulant use & 2.08 & $(1.11,3.90)$ & .02 \\
\hline $\begin{array}{l}\text { Other drug use } \\
\text { (no cannabis) }\end{array}$ & 1.48 & $(0.92,2.39)$ & .11 \\
\hline
\end{tabular}

${ }^{a}$ Statistical assessments of colinearity in the model are not significant.

was much higher than the generally accepted prevalence estimates for the population as a whole (0.5-1\% for $\mathrm{AN}, 1-3 \%$ for $\mathrm{BN}$, and $3-5 \%$ for EDNOS). To our knowledge, this study represents the first report on the screening for eating disorders in an ED setting so we have no means of direct comparison to other ED-based studies. Our findings were, however, consistent with rates of $7-21 \%$ seen in other studies of screening with the SCOFF both in the general population and in primary care settings. ${ }^{3-5}$ Given that the ED may serve as primary care for many patients, it seems logical that rates of patients screening positive for eating disorders are similar between the two settings. The ED may rep- resent the only access to healthcare for many adolescents and young adults and, therefore, may also be the only opportunity for intervention by a healthcare provider. This is important as duration of illness is a strong predictor of outcome in eating disorders with the likelihood of recovery decreasing dramatically with increasing length of illness. ${ }^{39}$

Another plausible explanation for the high rates of positive screens in this study may be related to the use of the SCOFF in the ED population. Although its use has been validated in multiple other settings, there are no prior studies documenting use in the ED. Because a second, gold standard diagnostic test for eating disorders was not used to verify the positive SCOFF screens in the current study; it is possible that there is a significant rate of false-positive screens. Regardless, based on prior estimates for sensitivity (72-100\%) and specificity (73-94\%) for this instrument, ${ }^{5,27-29}$ the rates of true-positive screens are still likely to be much higher than prior population estimates for eating disorders. Whether or not these findings represent an actual increased incidence of eating disorders in this population is unclear at this point and will require further investigation. Future studies may also want to include a confirmatory test for eating disorders to further evaluate the use of the SCOFF in this population.

As expected, our results also indicate a significant association between eating disorders and both depression and substance use. A patient who screened positive for an eating disorder was three times more likely to also screen positive for depression and about twice as likely to report risky drinking behavior and/or stimulant use than a patient without a positive eating disorder screen. This is 
consistent with known high rates of comorbidity between these disorders and highlights a group of individuals who may be at particularly high risk for negative consequences. The presence of SUD and/ or mood disorder has been shown to be amongst the worst prognostic indicators in patients with eating disorder ${ }^{40}$ with severity of alcohol use being one of the strongest predictors of fatal outcome in patients with AN. ${ }^{24}$ In addition, the presence of any substance use more than doubles the risk of death in patients with co-occurring affective disorders. ${ }^{41,42}$ Conversely, the presence of an eating disorder has also been shown to negatively impact outcome among patients with alcohol use disorders. ${ }^{42}$ Severity of eating disorder may also correlate with severity of SUD and negative consequences of both disorders. ${ }^{43,44}$ For example, among adolescents in substance abuse treatment, Sterling and Weisner found that patients with a comorbid illness (i.e., mood or eating disorders) were significantly more likely to drop out of treatment and/or to relapse than those without. ${ }^{45}$ In this same study, findings indicated that those patients who received targeted treatment for their co-occurring mood or eating disorders along with treatment for substance use had significantly greater rates of abstinence following treatment than those who did not. ${ }^{45}$ Given that identification and treatment of comorbidities clearly enhance positive outcomes for individuals with eating disorders, depression, and SUD targeted screening of all individuals identified to have one or more of these conditions may be warranted in the ED setting to ensure essential follow-up care.

Young Caucasian women from middle- to upperincome groups have traditionally been considered the demographic at highest risk for developing eating disorders. In our sample, females were significantly more likely to screen positive for an eating disorder; however, no significant difference in the rates of eating disorders amongst different racial or income groups was seen. Nonetheless, it is important to note that in this study we have found a relatively high prevalence of eating disorders in males. In contrast to previous estimates that $<10 \%$ of eating disorders occur in males, ${ }^{46}$ this group accounted for $26.6 \%$ of the patients who screened positive in the current study. Although it is unclear whether these results represent a true increase in prevalence of eating disorders among males or are simply the result of increased reporting, these findings are consistent with those of other recent studies that have suggested an increasing overall prevalence of eating disorders that crosses all race and gender lines. ${ }^{46-48}$ Although in bivariate analyses those receiving public assistance were more likely to screen positive for an eating disorder, this variable was not significant in multivariate models. These results underscore the importance of maintaining a high index of suspicion for eating disorders in adolescents and young adults regardless of gender, ethnicity, and/or socioeconomic status.

Finally, patients in this study who screened positive for an eating disorder had, on average, a higher BMI and were significantly more likely to be overweight or obese than those who screened negative. On the surface, this may seem counterintuitive because many will associate eating disorders with patients who are underweight; however, this is actually an expected result based on the fact that only patients with AN, who represent the minority of eating disorder diagnoses, would be expected to be underweight. BN, BED, and other forms EDNOS are far more prevalent than AN and are by definition associated with normal weights and above. This is also consistent with prior findings that binge eating in both $\mathrm{BN}$ and BED is strongly associated with obesity and high levels of psychiatric comorbidity. ${ }^{48}$

\section{Limitations}

Several limitations of this study require mentioning, including the cross-sectional design, which limits interpretation of causality. In addition, findings from this single-site study may not generalize to other ED settings, and replication is needed with larger and more diverse ED samples. Also, as mentioned above, the use of the SCOFF as a screening tool has not been previously validated in the ED setting. Future studies should include comparison with an established gold standard eating disorder diagnostic instrument to further evaluate its use in this patient population.

\section{Conclusion}

Eating disorders are common amongst 14- to 20year-old patients presenting to the ED for medical care. In this population, they are significantly associated with alcohol and other substance use, depression, and an elevated BMI and are also present at higher rates among males and minorities than previously reported. Future prevention, screening, and intervention programs for eating disorders, depression, and substance use in acute care settings should account for these important and prevalent comorbidities. 
The authors thank project staff for their work on the project including Carrie Smolenski. They also thank Stephanie Harrison, M.S., and Linping Duan, M.S., for statistical support. Finally, special thanks are owed to the patients and medical staff at the University of Michigan Medical Center for their support of this project.

\section{References}

1. Chamay-Weber C, Narring F, Michaud P. Partial eating disorders among adolescents: A review. J Adolesc Health 2005;37:417427.

2. Fairburn C, Cooper Z, Doll H, Norman P, O'Connor M. The natural course of bulimia nervosa and binge eating disorder in young women. Arch Gen Psychiatry 2000;57:659-665.

3. Hautala L, Junnila J, Alin J, Gronroos M, Maunula A-M, Karukivi $M$, et al. Uncovering hidden eating disorders using the SCOFF questionnaire: Cross-sectional survey of adolescents and comparison with nurse assessments. Int J Nurs Stud 2009;46:1439 1447.

4. Johnston O, Fornai G, Cabrini S, Kendrick T. Feasibility and acceptability of screening for eating disorders in primary care. Fam Pract 2007;24:511-517.

5. Mond J, Myers T, Crosby R, Hay P, Rodgers B, Morgane J, et al. Screening for eating disorders in primary care: EDE-Q versus SCOFF. Behav Res Ther 2008;46:612-622.

6. Ogg E, Millar H, Pusztai E, Thom A. Genreal practice consultation patterns preceding diagnosis of eating disorders. Int J Eat Disord 1997;22:89-93.

7. Striegel-Moore R, Dohm F, Kraemer H, Schreiber G, Crawford P, Daniels $S$. Health services use in women with a history of bulimia nervosa or binge eating disorder. Int J Eat Disord 2005;37:11-18.

8. Crow S, Praus B, Thuras P. Mortality from eating disorders-A 5- to 10-year record linkage study. Int J Eat Disord 1999;26:97101.

9. Godart N, Perdereau F, Rein Z, Berthoz S, Wallier J, Jeammet P, et al. Comorbidity studies of eating disorders and mood disorders. Critical review of the literature. J Affect Disord 2007;97:37-49.

10. Sinha R, O'Malley S. Alcohol and eating disorders: Implications for alcohol treatment and health services research. Alcohol Clin Exp Res 2000;24:1312-1319.

11. Krug I, Poyastro Pinheiro A, Bulik C, Jiménez-Murcia S, Granero R, Penelo E, et al. Lifetime substance abuse, family history of alcohol abuse/dependence and novelty seeking in eating disorders: Comparison study of eating disorder subgroups. Psychiatry Clin Neurosci 2009;63:82-87.

12. Piran N, Robinson S. Associations between disordered eating behaviors and licit and illicit substance use and abuse in a university sample. Addict Behav 2006;31:1761-1775.

13. Pisetsky E, Chao Y, Dierker L, May A, Striegel-Moore R. Disordered eating and substance use in high-school students: Results from the youth risk behavior surveillance system. Int J Eat Disord 2008;41:464-470.

14. Bulik C, Klump K, Thornton L, Kaplan A, Devlin B, Fichter M. Alcohol use disorder comorbidity in eating disorders: A multicenter study. J Clin Psychiatry 2004;65:1000-1006.

15. Root T, Pyastro Pinheiro A, Thornton L, Strober M, FernandezAranda $\mathrm{F}$, Brandt $\mathrm{H}$, et al. Substance use disorders in women with anorexia nervosa. Int J Eat Disord 2010;43:14-21.

16. CASA, editor. The National Center on Addiction and Substance Abuse (CASA) at Columbia University. Food for Thought: Sub- stance Abuse and Eating Disorders. New York: The National Center on Addiction and Substance Abuse at Columbia University, 2003.

17. Krug I, Treasure J, Anderluh M, Bellodi L, Cellini E, di Bernardo M. Present and lifetime comorbidity of tobacco, alcohol and drug use in eating disorders: A European multicenter study. Drug Alcohol Depend 2008;97:169-179.

18. Birmingham C, Su J, Hlynsky J, Goldner E, Gao M. The mortality rate from anorexia nervosa. Int J Eat Disord 2005;38:143-146.

19. Crow S, Mitchell J, Pyle R, Eckert E, Raymond N. Mortality from EDNOS. Presented at the Eating Disorders Research Society Meeting, Pittsburgh, PA, 2007.

20. Crow S, Peterson C, Swanson S, Raymond N, Specker S, Eckert E, et al. Increased mortality in bulimia nervosa and other eating disorders. Am J Psychiatry 2009; AiA:1-5.

21. Harris E, Barraclough B. Excess mortality of mental disorder. $\mathrm{Br}$ J Psychiatry 1998;173:11-53.

22. Pompili M, Girardi P, Tatarelli G, Ruberto A, Tatarelli R. Suicide and attempted suicide in eating disorders, obesity and weightimage concern. Eat Behav 2006;7:384-394.

23. Franko D, Keel P, Dorer D, Blais M, Delinsky S, Eddy K, et al. What predicts suicide attempts in women with eating disorders? Psychiatr Med 2004;34:843-853.

24. Keel P, Dorer D, Eddy K, Franko D, Charatan D, Herzog D. Predictors of mortality in eating disorders. Arch Gen Psychiatry 2003;60:179-183.

25. Lowenstein S, Koziol-McLain J, Thompson M, Bernstein E, Greenberg K, Gerson L, et al. Behavioral risk factors in emergency department patients: A multisite survey. Acad Emerg Med 1998;5:781-787.

26. WHO. Physical status: The use and interpretation of anthropometry. Report of a WHO Expert Committee. WHO Technical Report Series 854. Geneva: World Health Organization, 1995.

27. Cotton M, Ball C, Robinson P. Four simple questions can help screen for eating disorders. J Gen Intern Med 2003;18:53-56.

28. Luck A, Morgan J, Reid F, O’Brien A, Brunton J, Price C, et al. The SCOFF questionnaire and clinical interview for eating disorders in general practice: Comparative study. $\mathrm{Br}$ Med J 2002;325:755-756.

29. Morgan J, Reid F, Lacey J. The SCOFF questionnaire: Assessment of a new screening tool for eating disorders. $\mathrm{Br}$ Med J 1999;319:1467-1468.

30. Spitzer R, Kroenke K, Williams J. Validation and utility of a selfreport version of PRIME-MD; The PHQ primary care study. JAMA 1999;282:1737-1744.

31. Kroenke K, Spitzer R, Williams J. The patient health questionnaire-2 validity of a two-item depression screener. Med Care 2003;41:1284-1292.

32. Arroll B, Goodyear-Smith F, Crengle S, Gunn J, Kerse N, Fishman T, et al. Validation of PHQ-2 and PHQ-9 to screen for major depression in the primary care population. Ann Fam Med 2010;8:348-353.

33. Chung T, Colby S, Barnett N, Monti P. Alcohol Use Disorders Identification Test: Factor structure in an adolescent emergency department sample. Alcohol Clin Exp Res 2002;26:223231.

34. Kelly T, Donovan J, Chung T, Bukstein O, Cornelius J. Brief screens for detecting alcohol use disorder among 18-20 year old young adults in emergency departments: Comparing AUDIT-C, CRAFFT, RAPS4-QF, FAST, RUFT-Cut, and DSM-IV 2Item Scale. Addict Behav 2009;34:668-674.

35. Reinert D, Allen J. The Alcohol Use Disorders Identification Test: An update of research findings. Alcohol Clin Exp Res 2007;31:185-199.

36. Dawson D, Grant B, Stinson F, Zhou Y. Effectiveness of the derived Alcohol Use Disorders Identification Test (AUDIT-C) in 


\section{DOOLEY-HASH ET AL.}

screening for alcohol use disorders and risk drinking in the US general population. Alcohol Clin Exp Res 2005;29:844-854.

37. Babor T, Group WAW. The Alcohol, Smoking and Substance Involvement Screening Test (ASSIST): Development, reliability and feasibility. Addiction 2002;97:1183-1194.

38. Hosmer D, Lemeshow S. Applied Logistic Regression. New York: Wiley, 2000.

39. Treasure J, Russell G. The case for early intervention in anorexia nervosa: Theoretical exploration of maintaining factors. $\mathrm{Br}$ J Psychiatry 2011;199:5-7.

40. Berkman N, Lohr K, Bulik C. Outcomes of eating disorders: A systematic review of the literature. Int J Eat Disord 2007;40:293-309.

41. Herzog DB, Greenwood DN, Dorer DJ, Flores AT, Ekeblad ER, Richards A, et al. Mortality in eating disorders: A descriptive study. Int J Eat Disord 2000;28:20-26.

42. Franko DL, Dorer DJ, Keel PK, Jackson S, Manzo MP, Herzog DB. How do eating disorders and alcohol use disorder influence each other? Int J Eat Disord 2005;38:200-207.
43. Anderson D, Martens M, Cimini M. Do female college students who purge report greater alcohol use and negative alcoholrelated consequences? Int J Eat Disord 2005;37:65-68.

44. Killeen TK, Greenfield SF, Bride BE, Cohen L, Gordon SM, Roman PM. Assessment and treatment of co-occurring eating disorders in privately funded addiction treatment programs. Am J Addict 2011;20:205-211.

45. Sterling S, Weisner C. Chemical dependency and psychiatric services for adolescents in private managed care: Implications for outcomes. Alcohol Clin Exp Res 2005;29:801-809.

46. Domine' F, Berchtold A, Akre' C, Michaud P, Suris J. Disordered eating behaviors: What about boys? J Adolesc Health 2009;44:111-117.

47. Shaw H, Ramirez L, Trost A, Randall P, Stice E. Body image and eating disturbances across ethnic groups: More similarities than differences. Psychol Addict Behav 2004;18:12-18.

48. Hudson JI, Hiripi E, Pope HG Jr, Kessler RC. The prevalence and correlates of eating disorders in the National Comorbidity Survey Replication. Biol Psychiatry 2007;61:348358. 